\title{
Some Comments about the Object and Realization of Neutrality as Fair Treatment in Alan Patten's Equal Recognition
}

\begin{abstract}
Aurélia Bardon
In Equal Recognition, Alan Patten aims at providing a firm philosophical foundation to minority rights. The main problem with the usual multiculturalist arguments defending such rights is that they are based on controversial conceptions of culture that are at odds with liberal neutrality. To avoid such difficulty, Patten's argument for strong cultural rights is based on a commitment to neutrality. In a surprising way, the key concept of Patten's book on recognition, minority rights, and culture is then liberal neutrality.

Neutrality, Patten convincingly argues, should be understood as neutrality of treatment rather than neutrality of effects or neutrality of intentions. ${ }^{1}$ Fair treatment can be achieved in three different ways: privatization, generic entanglement, and evenhandedness. ${ }^{2}$ Privatization is the best way to realize neutrality, and the two other strategies "will at best approximate neutrality." 3 But in the case of culture, privatization and generic entanglement, which are both forms of nonrecognition, ${ }^{4}$ are not an option: the state cannot be completely culturally neutral. Some recognition is, therefore, unavoidable. This leaves us with only two alternatives: majoritarian recognition, or equal recognition. Patten then argues that "the majoritarian approach to recognition is plainly nonneutral,",$"$ and therefore that the best strategy to realize neutrality toward culture is equal recognition.

There are two different points in this argument that might be challenged. First, we might disagree about what Patten calls the "domain of neutrality," i.e. the type of conceptions of the good to which neutrality should apply. Second,

\footnotetext{
* Aurélia Bardon, University College London, School of Public Policy. Email: a.bardon@ucl.ac.uk. Research for this article has been funded by the European Research Council (ERC) Grant 283867 on "Is Religion Special?"

1 Alan Patten, Equal Recognition: The Moral Foundations of Minority Rights 112 (2014)

Id. at 119 .

${ }^{3} I d$. at 122 .

Id. at 169

${ }^{5}$ Id. at 165 .
} 
we might question the relation between recognition, nonrecognition and neutrality: I argue that recognition does not necessarily entail unfair treatment, and that nonrecognition does not necessarily entail fair treatment.

\section{Neutrality, conceptions of the good and preferences}

First, I want to look at the concept of neutrality and more specifically at its object, at the cases in which neutrality should apply and the cases in which neutrality is less important.

Patten's interpretation of neutrality as fair treatment is very convincing: the state is neutral towards A and B when it treats A and B fairly. This might mean that $\mathrm{A}$ and $\mathrm{B}$ are not treated equally in the sense that they are not equally successful, but this is not what liberal neutrality is interested in. The shortcomings of neutrality of effects are quite clear, and neutrality of effects or consequential neutrality is often considered by liberals as an impractical goal. ${ }^{6}$ It is also clear that neutrality of intentions cannot be sufficient, since it could lead to clearly unfair situations. One could probably argue that neutrality of intentions, at least in the form of justificatory neutrality, should be combined with neutrality of treatment, that each is insufficient on its own and that both would be the two sides of liberal neutrality, but this would not be incompatible with Patten's conception of neutrality of treatment.

The difficulty lies, however, in the identification of the proper object of neutrality. In other words, we should expect all liberals to agree that neutrality means that the state should treat A and B fairly, but we should also expect them to disagree about what $\mathrm{A}$ and $\mathrm{B}$ are. And although Patten justifies at length how neutrality is realized, what it means and why it is a very important commitment of liberalism, he is much more vague in the book, including in the chapter dedicated to the concept of liberal neutrality, regarding the object of neutrality. ${ }^{7}$ What, then, should the liberal state be neutral towards?

The liberal state, Patten argues, "has a responsibility to be neutral toward the various conceptions of the good that are affirmed by its citizens." ${ }^{8}$ The idea that neutrality is about conceptions of the good is a common liberal claim. Conceptions of the good have two characteristics that justify that neutrality should apply. First, they are about the good, i.e. they are about something that is controversial, over which citizens will disagree. This also implies that they are not about matters of justice or about political values such as equality or freedom: neutrality, therefore, does not apply to different conceptions of justice. Second, they are conceptions that matter to people who hold

\footnotetext{
${ }^{6}$ Simon Clarke, Contractarianism, Liberal Neutrality and Epistemology, 47 Political STUdies 628 (1999); JoHN Rawls, Political Liberalism 194 (1993); George Sher, Beyond Neutrality: Perfectionism and Politics 22 (1997).

${ }^{7}$ See Patten, supra Chapter 4.

${ }^{8}$ Id. at 104 .
} 
them: ${ }^{9}$ conceptions of the good are often interpreted as claims of conscience that have a special importance in people's lives. Not all conceptions of the good, however, should be treated neutrally. Two kinds of conceptions of the good are excluded from the "domain of neutrality:" 10 conceptions that reject the value of self-determination and worthless conceptions of the good. This restriction of the domain of neutrality is justified by the fact that neutrality is a "downstream value," i.e. it is justified by a commitment to self-determination.

What is more problematic is the justification of another distinction suggested by Patten but not fully defended: the distinction between what can be called deep commitments, that refer to the conceptions of the good that are in the domain of neutrality, and preferences that do not require the same degree of fair treatment, or maybe do not require fair treatment at all, like in the case of expensive tastes. The absence of a firm distinction appears in Patten's discussion of Barry's objection from expensive tastes: the distinction between neutrality of treatment and neutrality of effects only changes the focus of the objection, it does not provide a response to it. Because Patten does not use the conception of neutrality of effects, it does not matter that expensive tastes benefit from equal achievement: neutrality of effects is interested in whether different conceptions of the good are equally successful, but neutrality of treatment is only interested in whether different conceptions of the good enjoy equal (prorated) recognition. However, pointing that the unequal achievement of expensive tastes is not an objection to his argument does not tell us why we should not be worried about the unequal recognition of these expensive tastes. Here, Patten's argument is in fact circular: his response is already part of how he defines expensive tastes, as "those preferences that are relatively unsuccessful under fair background conditions." "I1 In other words, expensive tastes presuppose fair background conditions, i.e. it presupposes that whatever the liberal state should be neutral towards is already treated neutrally, and therefore that expensive tastes themselves should not be treated neutrally. This begs the question: why aren't expensive tastes part of the domain of neutrality in the first place? Or, in other words, how do we know whether a specific preference is an expensive taste or the kind of conception of the good that should be treated neutrally?

Patten suggests one possible strategy to justify the distinction between deep commitments and preferences, and to explain why neutrality applies only or more to the former: deep commitments are special commitments, and preferences are not. Special commitments are characterized by three factors: the commitment has a pivotal role in an individual's conception of the good, it has a nonnegotiable character, and it has recognitional salience. ${ }^{12}$ Patten insists

\footnotetext{
${ }^{9}$ Id. at 203.

${ }^{10} \mathrm{Id}$. at 109.

$11 \mathrm{Id}$. at 179 .

${ }^{12} \mathrm{Id}$. at 133-35.
} 
on the importance of the nonnegotiable character and claims that neutrality of treatment is "especially robust when it applies to aspects of conceptions of the good that involve religion and conscience, culture, family, sexuality, artistic endeavor, and other goods that are likely to seem nonnegotiable to the individual," but it is "less robust with respect to many preferences regarding leisure and ordinary consumption, which are unlikely to have a nonnegotiable character." ${ }^{\prime 3}$ This way to justify the distinction between deep commitments and preferences is however problematic: I identify two possible objections.

The first objection is that it confuses an objective distinction, based on what the preference is about, with a subjective distinction based on the role or importance it can have, or with the interest that the individual might have in the realization of this preference. The objective distinction means that deep commitments and preferences are different in a normatively relevant way because they have different objects: deep commitments would be about religion, conscience or culture, whereas preferences would be about leisure. The subjective distinction means that deep commitments and preferences are different in a normatively relevant way because of what they mean for the individual holding them: deep commitments would be extremely important and nonnegotiable, whereas preferences would not play such an important role in their life, their conception of the good or their identity. But the objective distinction between on the one hand, preferences about religion, conscience or culture and, on the other hand, preferences about leisure and ordinary consumption, does not perfectly overlap with the subjective distinction between negotiable and nonnegotiable preferences; this seems to be accepted by Patten who writes that the overlap is only likely to exist and is not necessary. We cannot exclude the possibility that what many of us would consider as a sporting or recreational preference might play a pivotal role in someone's conception of the good, might be nonnegotiable or might have recognitional salience. The reverse is also true: many people do not consider religion as a special commitment, and it seems reasonably to consider that certain particular preferences associated for instance with sexuality or artistic endeavor are more about superficial preferences than about deep commitments. Patten might then agree to reformulate the argument in the following way: neutrality is especially robust when it applies to special commitments, whether they are about culture, sexuality or leisure, and less robust when it applies to superficial preferences. But this would have two problematic implications. The first would be that this would make it impossible to single out cultural claims as being special, and therefore the argument might support strong conscience rights but not strong cultural rights. Second, there would be a serious practical and moral problem in identifying the distinction in real cases, since it would mean that we should assess the importance of different claims in an individual's conception of the good;

${ }^{13} I d$. at 136 . 
the idea of evaluating the content or depth of claims of conscience of individuals will probably be received with legitimate concerns by liberals. We can imagine how this might lead to cases where people would have to judge whether a certain preference, held by someone else, is in fact a special commitment or not: it is what led, for instance, to disconcerting situations, such as when those defending the minarets ban in Switzerland, or those defending the prohibition of the Muslim veil in schools in France insisted that minarets and veils are basically expensive tastes and that they are not directly required by religious commitments.

The second objection has to do with the relation between special commitments and a more robust requirement of neutrality. The idea that the specialness of commitments would particularly justify neutrality might be challenged. It is in fact not immediately clear why claims of conscience should be more important than more superficial preferences. This idea of the importance of claims of conscience is shared by many liberals, including by egalitarians who would reject the idea of cultural rights. And yet, it assumes some kind of special liberal commitment to the protection of conscience that is not at all obvious or directly related to the core claims of liberalism. Liberals are interested in self-determination and in liberty, but it is not at all clear that the reasons an individual has to want to do something should matter to decide whether he should be allowed to do it or not. This problem seems particularly obvious in cases where special accommodation would be given on the grounds of deep commitments, but not on the grounds of more superficial preferences. This would suggest, for instance, that the state should not accommodate in the same way those who are vegetarians as a result of deep commitments, religious or not, and those who simply dislike the taste of meat in general. It would be very difficult to show that this does not entail that the state is not treating people as equal or as having the same rights.

\section{Recognition and fair treatment}

The second set of comments focuses on the relation between recognition, equal recognition, and neutrality as fair treatment. I try to show first that recognition does not necessarily entail unfair treatment, and second that the absence of recognition does not necessarily entail fair treatment.

The first point that might be challenged is that recognition of a majoritarian culture is necessarily incompatible with neutrality. ${ }^{14}$ Although it seems obvious in a superficial sense that societies and states are always recognizing one specific culture, or several specific cultures, and not others, what remains to be demonstrated is that this is a breach of liberal neutrality in a meaningful sense.

${ }^{14} I d$. at $167-69$. 
We all agree that a state cannot be completely neutral in the sense that it always associated with a language, with a specific culture, and probably with a specific religion as well (although this seems to be denied by Patten). Culture cannot be fully privatized. The objection here would be the following: depending on the way in which the state is associated with culture, it cannot always be concluded that it corresponds in fact to a breach of liberal neutrality since neutrality does not mean equal treatment or equal effects on all citizens (including, presumably, of all different cultures or religions). Simply observing that there is an unequal recognition of certain cultures or certain conceptions of the good can only be interpreted as a breach of liberal neutrality if by neutrality we mean neutrality of effects. But if, as Patten argues, a breach of neutrality is the result of policies that accommodate certain cultures more than others, and not of indirect effects of otherwise neutral policies, then it remains to be shown how exactly liberal states are accommodating culture in an unfair way, i.e. how this accommodation actually entails a lack of fair opportunity to develop and realize other conceptions of the good. I am not convinced that this is necessarily the case. Neutrality of treatment means that, within the domain of neutrality, the state should not accommodate some conceptions of the good more than others: "If the state adopts some policy that can be expected, in conjunction with other necessary inputs, to make a particular conception of the good more successful, then, in my terminology, its policy is 'accommodating' toward that conception." 15 There are many examples, however, of cases where specific conceptions are accommodated more than others, where we actually hope to make certain conceptions more successful than others, and where this would not sound like a serious problem. Some people believe, for instance, that there is, today in liberal democracies, a special political accommodation of certain ideas concerning gender and sexuality. More specifically, some people believe that the state is imposing, or at least promoting, the idea that there are no different natural roles for men and women or that heterosexuality and homosexuality are both equally valid options. Based on Patten's argument, there is no reason to consider that the beliefs of those who disagree with such ideas, would not belong to the domain of neutrality: they concern questions of morality and not of justice, they do not reject self-determination and there is little doubt that they are considered as being special commitments. People holding such beliefs might however argue, and I believe they would have a point, that what the state is doing, especially in public schools, promotes more progressive conceptions of the good regarding gender and homosexuality over more conservative ones, and that therefore the state is making those progressive conceptions of the good more successful. In this case, I believe we should admit that we are in fact treating these different conceptions unequally; but I also believe we have very good reasons to do so, and therefore that

${ }^{15} I d$. at 115. 
unequal treatment here is not a breach of liberal neutrality in a meaningful sense, and that the fact that the state accommodates certain conceptions more than others does not necessarily mean that this is unfair.

It might be, then, that in certain cases and under certain conditions, unequal recognition would not necessarily entail a lack of fair treatment. And I would argue that this can notably be the case for religion. Patten discusses briefly the question of religious establishment, that he uses as an objection against neutrality of intentions or neutrality of justification: he rightly notes that "neutrality of intentions does not regard all cases of state establishment as departures from neutrality." 16 There can indeed be neutral reasons to establish a particular religion, not because that religion is considered to be true but because "its establishment will bring desirable social consequences". ${ }^{17}$ But although the justification itself might be neutral, Patten claims that "the policy still involves an official state preference for one particular religion and would strike many people as plainly nonneutral in character." ${ }^{18}$ What is not so clear is that this preference alone is enough to conclude that there has been a particular assistance or accommodation of the religious conception of the view that the established religion represents. An example will illustrate this point: England, like several other European countries, has an established church. It might be the case that this would be considered by certain citizens as a symbolic imposition of conceptions of the good associated with the Church of England. But is there really an unfair treatment here? Or, rather, to the extent that there is unfair treatment, is it really because of the establishment of the church? Clearly, religious establishment is not incompatible with religious freedom and individuals who are not members of the Church of England, who might be members of another religion or who might be non-religious, have the exact same rights as the members of the Church of England. Besides, the Church does not exercise any political authority and does not receive any public funding from the state. The unfairness is not in the actual but in the symbolic treatment. There are deep disagreements about what should be done concerning such symbolic unfair treatment. Brian Barry, for instance, argued that religious establishment in the case of England or Sweden is a "venial" departure from neutrality, "so long as nobody is put at a significant disadvantage, either by having barriers put in the way of worshipping according to the tenets of his faith or by having his rights and opportunities in other matters (politics, education, or occupation, for example), materially limited on the basis of his religious beliefs:"19 in other words, this kind of weak or superficial recognition would not be problematic. Martha Nussbaum, on the other hand, considers that religious establishment threatens the equality of citizens, since it

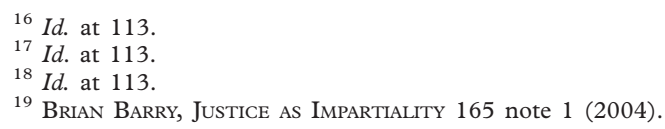


"suggests that nonadherents are not fully equal members of the political community." 20 Symbolically, it is true that those who are not members of the Church of England might feel like they are not fully equal citizens. But it is not clear that this would change if the Church of England were disestablished. It seems much more likely that what justifies the feeling of symbolic inequality has to do with many other ways in which religious majorities discriminate against religious minorities. It is pretty obvious, for instance, that the same kind of symbolic unfair treatment exists in France as well, maybe even more than in England, although there is no religious establishment. The way in which citizens treat each other, and more particularly the way in which members of the cultural and religious majority treat members of the cultural and religious minorities, should be expected to be much more important factors than weak forms of cultural and religious recognition in explaining symbolic unfair treatment. And although there are ways in which the state can and should attempt to change this, it is very unclear that the disestablishment of the Church of England would help in any way.

The second point that might be challenged is the relation between nonrecognition and neutrality. Here, I focus more specifically on religious neutrality, and on what Patten tells us about neutrality towards religion. Patten claims that neutrality is actually pretty easy to achieve when it comes to religion, because one can simply use nonrecognition, which is even better than equal recognition to guarantee fair treatment: consequently, "the state can and probably should avoid recognizing any religion," 21 although this strategy would be unavoidable for culture because cultural nonrecognition is simply impossible. I agree that perfect cultural nonrecognition is impossible; but the idea that there could be perfect religious nonrecognition, or that liberal neutrality towards religion would be more easily achievable than liberal neutrality towards culture, sounds problematic for two reasons.

First, the liberal state cannot be completely neutral towards religion because it will have to choose among the following alternatives: recognizing one religion, recognizing several religions, or recognizing no religion. Let's assume that we agree that majoritarian recognition is unfair and not neutral; there is still an unavoidable choice to be made between recognizing all religions and recognizing no religion. The problem is that, in the case of religion, and contrary to what Patten claims, nonrecognition is not more neutral than equal recognition: nonrecognition accommodates secular conceptions of the good more than religious ones, and in the same way equal recognition accommodates religious conceptions of the good more than secular ones. It would be hard to deny that secularism is itself a controversial conception of the good. ${ }^{22}$ Consequently,

\footnotetext{
${ }^{20}$ Martha Nussbaum, Liberty of Conscience 225 (2008).

${ }^{21}$ Patten, supra 250.

${ }^{22}$ Cécile Laborde, Political Liberalism and Religion: On Separation and Establishment, 21 J. Political Philos. 74 (2013).
} 
secularism and separation of church and state should be considered as "a form of assistance to one or more conceptions of the good:" 23 in other words, religious nonrecognition cannot mean religious neutrality. And yet, I believe that this is not necessarily problematic, and that we should not conclude that secularism and separation of church and state are nonneutral in a meaningful way, i.e. that it would be a breach of liberal neutrality.

Second, the state cannot be completely neutral toward religion because it cannot avoid legislating about religious matters. When the state legislates about religious matters, it cannot avoid accommodating particular religious doctrines more than others. This is in fact an objection that has been developed recently by several critical theorists, who have argued that the liberal state, and more specifically the liberal secular state, is not at all neutral and in fact imposes a specific conception of religion, and that religious neutrality is a myth: "the claim of religious neutrality, on the basis of which secularism asserted the authority to adjudicate the limits of the various religions, especially vis-à-vis the secular, stands revealed as myth." ${ }^{24}$ It is more particularly through law that the impossibility of religious neutrality is revealed: "when courts determine that some practices are not religious and, hence, do not fall under the scope of religious freedom, or do not deserve state funding or tax exemption, the failure to be religiously neutral seems inevitable." ${ }^{25}$ What those critical theorists highlight is that the conception of what a religion is will have important nonneutral implications. More particularly, they argue that law in liberal democracies has been greatly influenced by a Protestant understanding of religion, which actually appears pretty clearly in Patten's argument, since this Protestant understanding is closely related with the privatization strategy, which Patten recommends to realize neutrality towards religion. In other words, the privatization strategy in itself can be interpreted as accommodating certain religions more than others, since it would fit much more with religions that are individualistic, liberal, and modern, religions that emphasize the role and the importance of conscience and that are compatible with the separation between religion and politics. My point here is not at all to criticize this particular accommodation of a certain conception of religion. In fact, I believe that this particular accommodation is perfectly justifiable. But I would agree with the critical theorists that this cannot be considered as neutral, neither in terms of effects nor in terms of fair treatment.

Patten's focus on neutrality might well be considered as problematic by some liberals. I have here given some comments about what Patten says about the object and the realization of neutrality as fair treatment, but there could be

\footnotetext{
${ }^{23}$ Patten, supra 112.

${ }^{24}$ Robert A. Yelle, Moses' Veil: Secularization as Christian Myth, in After Secular Law 35 (Winnifred Fallers Sullivan, Robert A. Yelle and Mateo Taussig-Rubbo, 2011).

${ }^{25}$ Karl de Roover, Secular Law and the Realm of False Religion, in AFTer SECUlar Law 43 (Winnifred Fallers Sullivan, Robert A. Yelle and Mateo Taussig-Rubbo, 2011).
} 
discussions as well about the conception of neutrality as fair treatment, rather than as neutrality of effects or justificatory neutrality, and about the justification of neutrality itself, i.e. why liberals are committed to neutrality in the first place. But it is precisely one of the most important achievements of this book to show that liberals are not done talking about neutrality, and that the concept is still a haunting one in liberal political theory. As Alan Patten had very clearly stated in his introduction, the main disagreements with his argument are to be expected not at the level of the particular policies or decisions for specific cases, but at the level of the justification for these policies and decisions. ${ }^{26}$ In other words, although most liberals will accept Patten's suggestions as to when and how to grant language rights or under which conditions to allow secession, some will object that this has anything to do with liberal neutrality, with culture or with equal recognition.

${ }^{26}$ Patten supra 10. 